$\xi=$

\title{
Taurine represses oxidative stress in the liver and kidney following exposure to atrazine in Wistar rats
}

\author{
Olusegun Kayode Afolabi ${ }^{1}{ }^{*}$, Dasola Teslim Folarin ${ }^{1}$, Felix Olusola Aderibigbe ${ }^{1}$, Abimbola Arinola ${ }^{1}$ \\ ${ }^{1}$ Department of Biochemistry, Faculty of Basic Medical Sciences, Ladoke Akintola University of Technology, \\ P.M.B. 4000, Ogbomoso, Nigeria \\ *Corresponding author E-mail: okafolabi@lautech.edu.ng
}

\begin{abstract}
Background: Taurine is a conditional essential nutrient in man, with proven antioxidant property. This study was designed to evaluate the protective effects of taurine against atrazine (ATZ)-induced hepatic and renal oxidative toxicity in rats.

Methods: Wistar rats were orally exposed to ATZ (1/10 LD50) alone or in combination with taurine at $1.5 \%$ w/v and $3 \%$ w/v in their drinking water for 30 days. After treatment, the liver and kidney were excised for biochemical assays by spectrophotometric methods. Results: Exposure to ATZ significantly elevated hepatic and renal malondialdehyde (MDA) levels when compared to control ( $\mathrm{p}<0.05$ ). Advanced oxidized protein products (AOPP) were equally increased in these tissues on exposure to ATZ. In addition, reduced glutathione (GSH) and total antioxidant capacity (TAC) were markedly depleted in both organs on exposure to ATZ. Furthermore, activities of the antioxidant enzymes, superoxide dismutase (SOD) and catalase (CAT) were inhibited by ATZ compared to the control. However, cotreatment with taurine attenuated the oxidative responses generated by ATZ exposure in the rats, with the high dose of the amino acid normalizing most of the toxic effects.

Conclusion: The study suggested that taurine can protect against ATZ-induced oxidative stress.
\end{abstract}

Keywords: Antioxidant; Atrazine; Oxidative stress; Pesticide; Taurine.

\section{Introduction}

There has been an increase in the level of environmental pollution, partly due to the extensive usage of pesticides in agriculture (Feng et al., 2017). Increase in labor cost and low rotation of crops have made herbicides the most commonly used class of pesticides (Klaassen and Amdur, 2013). Studies have associated pesticide exposure with chronic health problems, including neurological defects, reproductive toxicities, and birth defects among others (Lushchak et al., 2018). Atrazine (2-chloro-4-ethylamino-6-isopropylamino-s-triazine) is a widely used herbicide belonging to the class of chloro-s- triazine herbicides and is used to control weeds in a number of triazine-tolerant crops including maize, cereals, and sugarcane (Ross et al., 2009). Apart from plants, ATZ residues have been detected in soil and water, as well as, agricultural products like fruits, butter, milk and sugar beet (Singh et al., 2010). The widespread use and persistence of ATZ residues in the environment result in exposure to non-target organisms. Exposure to ATZ can occur during manufacturing operations and end-use applications (Gao et al., 2016). Although considered a low toxicity herbicide, studies have shown ATZ could produce toxic consequences ranging from endocrine and reproductive dysfunction to immunological disorder in both animals and humans (Bonvallot et al., 2018; Feng et al., 2017). Previous studies have also linked ATZ with DNA damage and erythrocyte membrane distortion in animals (Santos and Martinez, 2012). ATZ exposure has been connected with a depletion of the antioxidant defense system, indicating induction of oxidative stress (Abarikwu et al., 2017). The toxic manifestations identified with pesticides exposure, including ATZ have been associated with enhanced production of reactive oxygen species (ROS) (Singh et al., 2010). These ROS, which include superoxide anions, hydroxyl radicals, and hydrogen peroxide enhance the oxidative process and induce peroxidative damage to membrane lipids.

Taurine (2-aminoethanesulfonic acid) is a ubiquitous free amino acid found in most mammalian tissues (Jong et al., 2012). It is a conditionally essential nutrient in man (Schaffer and Kim, 2018). Various physiologic functions in cell metabolism have been assigned to this amino acid, including osmoregulation, membrane stabilization, protein phosphorylation and detoxification (Schaffer et al., 2010; Chen et al., 2019). Taurine has also been found to have protective effect against a variety of pathological conditions, including ischemia and neurotoxicity. It is known to exhibit a protective effect against oxidative stress and is a potent scavenger of hydroxyl radicals during cellular injury in different cells and tissues (Heidari et al., 2013). Taurine inhibits lipid peroxidation and increases the activities of antioxidant enzymes following chemical exposure (Yildirim and Kilic, 2011; Zhang et al., 2014). Studies have also shown that the antioxidant activity exhibited by taurine protects various tissues from oxidative stress induced by heavy metals, drugs and chemicals (Ozden et al., 2013; Roy and Sil, 2012; Alam et al., 2011). However, there has been no report on its protective effects against ATZ-induced toxicities. Although, the toxic effects of ATZ are well documented, insufficient information is available on the protective effect of Taurine against ATZ poisoning. Therefore, the current study aimed to investigate the antioxidant potentials and effects of taurine against ATZ-induced oxidative stress in rats. 


\section{Materials and methods}

\subsection{Chemicals}

Taurine, xylenol orange, tripyridyl-5-triazine (TPTZ), were procured from Sigma-Aldrich (Munich, Germany). Commercial grade atrazine marketed as Delzine ${ }^{\circledR}$ (Candel) was obtained from Irorun Agbe Agrochemical Company (Ogbomoso, Nigeria). Other chemicals and reagents were all of analytical grade.

\subsection{Animals and treatment}

Thirty-five male Wistar rats weighing 180-200 g procured from the Animal House, Faculty of Basic Medical Sciences, Ladoke Akintola University of Technology were used for the study. The animals were housed in plastic cages under controlled laboratory conditions of normal light-dark cycle $\left(12 \mathrm{~h}\right.$ light/dark) and temperature $\left(25 \pm 2^{\circ} \mathrm{C}\right)$. The animals were fed with pelleted diet and water ad libitum.

\subsection{Experimental design}

After a one-week acclimatization period, the animals were randomly divided into five groups of 7 rats each and were treated with ATZ and/or taurine daily, for 30 days, as follows:

1) Control: Animals were given feed and water only, for the duration of the experiment. This group served as a normal control group.

2) Tau: Taurine was orally administered to rats in this group in drinking water at a dose of $1.5 \% \mathrm{w} / \mathrm{v}$. This group served as a positive control group.

3) ATZ: Animals received ATZ alone at a dose of $300 \mathrm{mg} \mathrm{kg}^{-1}$ body weight, being 1/10 of LD50. This group served as a negative control.

4) $\mathrm{ATZ}+\mathrm{Tau}_{\mathrm{L}}$ : Rats in this group were administered ATZ (300 $\mathrm{mg} \mathrm{kg}^{-1}$ body weight) and taurine in their drinking water at $1.5 \%$ w/v, serving as low treatment group.

5) ATZ + Таuн: Animals in this group received the same treatment as group 4 but with a higher concentration of taurine at $3 \%$ w/v in their drinking water. This group served as high treatment group.

The doses of taurine used in this study were based on previous studies (Balkan et al., 2005; Dawson Jr et al., 2002) while the ATZ dose was to present a sub-lethal dose of the herbicide. At the end of the experiment, rats were lightly anaesthetized with ether. Liver and kidney were excised and processed for biochemical assays.

\subsection{Protein estimation}

The protein content of the organs was determined by the method of Lowry et al., (Lowry et al., 1951) using bovine serum albumin as a standard.

\subsection{Biochemical analyses}

\subsubsection{Determination of lipid peroxidation concentration}

Quantitative measurement of lipid peroxidation was performed in the tissue homogenates (Buege and Aust, 1978). The method is based on the formation of thiobarbituric acid reactive substances (TBARS) and expressed as the extent of malondialdehyde (MDA) production. Tissue homogenate was mixed thoroughly with a stock solution containing $15 \% \mathrm{w} / \mathrm{v}$ trichloroacetic acid, $0.375 \% \mathrm{w} / \mathrm{v}$ thiobarbituric acid and $0.25 \mathrm{M} \mathrm{HCl}$. The mixture was heated for $15 \mathrm{~min}$ and cooled. It was then centrifuged at $1000 \mathrm{~g}$ for 10 min and the absorbance of the supernatant determined at $535 \mathrm{~nm}$. Using an extinction coefficient of $1.56 \times 10^{5} \mathrm{M}^{-1} \mathrm{~cm}^{-1}$, the concentration of MDA was calculated and expressed as nmol per gram of wet tissue.

\subsubsection{Estimation of protein oxidation}

The level of protein oxidation in tissue was assessed by measuring advanced oxidized protein products (AOPP) (Witko-Sarsat et al., 1996). Homogenate of the sample was prepared with phosphate buffered saline and $1.16 \mathrm{M}$ potassium iodide and acetic acid were added. The absorbance of the reaction mixture was measured at $340 \mathrm{~nm}$ and an extinction coefficient of $26,000 \mathrm{mM}^{-1} \mathrm{~cm}^{-1}$ was used in calculating AOPP concentrations.

\subsubsection{Determination of total antioxidant capacity (TAC)}

The ferric reducing antioxidant power (FRAP) method described by Benzie and Strain (Benzie and Strain, 1996) was used in estimating the TAC in samples. FRAP working reagent was pre-warmed and then mixed with $10 \%$ homogenate of the sample. The procedure was performed at $37^{\circ} \mathrm{C}$, and the absorbance was read at $593 \mathrm{~nm}$.

\subsubsection{Determination of reduced glutathione (GSH)}

Levels of GSH in the organs were determined according to the method of Moron et al. (Moron et al., 1979), using 5,5'-dithiobis-2nitrobenzoic acid (DTNB) reagent. DTNB was reduced by free -SH group of GSH to form 5-mercapto-2- nitrobenzoate, and its absorbance was measured spectrophotometrically at $412 \mathrm{~nm}$.

\subsubsection{Determination of catalase (CAT) activity}

CAT activity in the tissues was assayed by the method of Aebi (Aebi, 1974). The decomposition of $\mathrm{H}_{2} \mathrm{O}_{2}$ was monitored spectrophotometrically at $240 \mathrm{~nm}$. The change in absorbance was the measure of CAT activity and expressed as nmol/mg protein. 


\subsubsection{Determination of superoxide dismutase (SOD) activity}

SOD activity was assayed according to the method of Misra and Fridovich (Misra and Fridovich, 1972) in the tissues. The addition of $0.01 \%$ epinephrine $(0.3 \mathrm{ml})$ to the mixture containing $2.5 \mathrm{ml}$ carbonate buffer $(0.05 \mathrm{M})$ and $0.2 \mathrm{ml}$ sample initiated the reaction. Change in absorbance was measured at $480 \mathrm{~nm}$, and the activity was expressed as unit per milligram of protein.

\subsection{Statistical analysis}

Data were analyzed by one-way analysis of variance, followed by Tukey's multiple comparisons test. Results were presented as mean \pm standard deviation (SD) and values were considered statistically significant at $\mathrm{p}<0.05$. Data were analyzed using GraphPad Prism for Windows, version 6.01 (GraphPad Software, Inc., San Diego, CA, USA.).

\section{Results}

\subsection{Malondialdehyde concentrations}

Figure 1 shows the concentrations of MDA in the liver and kidney of ATZ-exposed and treated rats. ATZ exposure induced significant increases in both hepatic and renal MDA levels compared to the control animals ( $\mathrm{p}<0.05)$. ATZ increased MDA contents in these tissues by $106 \%$ and $97 \%$ respectively. In the kidney, co-treatment with taurine reduced the concentrations of MDA drastically, with the high dose restoring the level to normal while in the liver, MDA contents were reduced by $39 \%$ and $43 \%$ in rats co-treated with low and high taurine doses respectively.

(A)

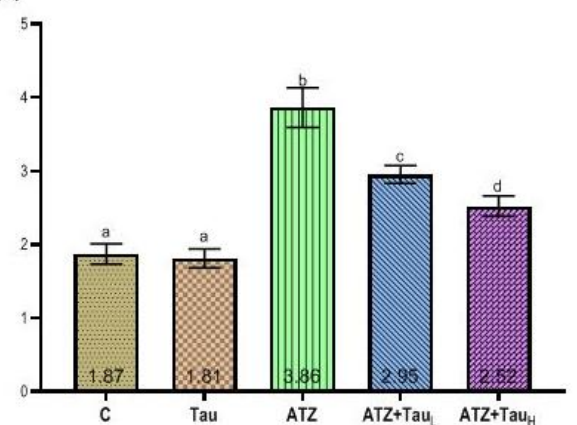

(B)

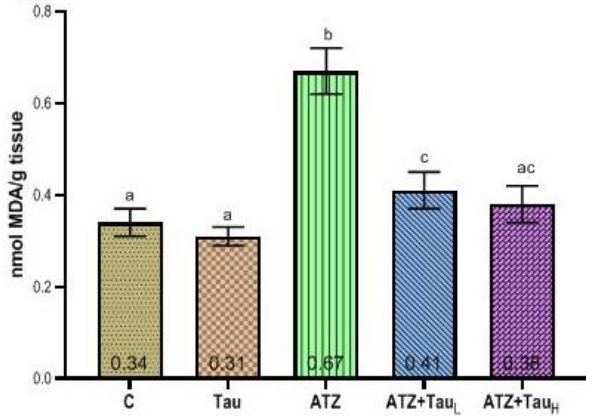

Fig. 1: Effects of ATZ Exposure and Taurine Treatment on Malondialdehyde (MDA) Concentration in the Liver (A) and Kidney (B) of Rats. Data are Presented as the Mean $\pm \mathrm{SD}(\mathrm{N}=7)$. Data with Different Superscripts are Significantly Different $(\mathrm{P}<0.05)$.

\subsection{Advanced oxidized protein products concentrations}

Figure 2 shows the concentrations of AOPP in the liver and kidney of ATZ-exposed and treated rats. The values of the protein oxidation index, AOPP in the organs were increased above normal in ATZ-exposed rats. In the liver, there was a 2-fold increase in AOPP contents while the exposure resulted in a 47\% increase in AOPP contents in the kidney. The pronounced levels of AOPP in liver and kidney were lowered by co-treatment with taurine. The reduction was more in the kidney where the high dose taurine led to a normalization of the AOPP content but yielded a $40 \%$ reduction in the liver.


Fig. 2: Effects of ATZ Exposure and Taurine Treatment on Advanced Oxidation Protein Products (AOPP) Concentration in the Liver (A) and Kidney (B) of Rats. Data are Presented as the Mean $\pm \mathrm{SD}(\mathrm{N}=7)$. Data with Different Superscripts are Significantly Different $(\mathrm{P}<0.05)$.

\subsection{Hepatic and renal concentrations of GSH}

Hepatic and renal GSH concentrations in the rats were markedly reduced by ATZ exposure when compared with the control ( $\mathrm{p}<0.05$ ). ATZ lowered GSH levels by $62 \%$ and $45 \%$ in the liver and kidney, respectively. In the liver, the high-dose taurine (3\% w/v) but not the low dose $(1.5 \% \mathrm{w} / \mathrm{v})$ restored reduced glutathione level to near normal value. Moreover, the kidney contents of GSH in ATZ-exposed animals were elevated by $37 \%$ and $63 \%$ respectively, on treatment with low and high dose taurine. Interestingly, taurine alone increased the GSH concentration in the liver by $25 \%$ compared to control (Figure 3 ). 

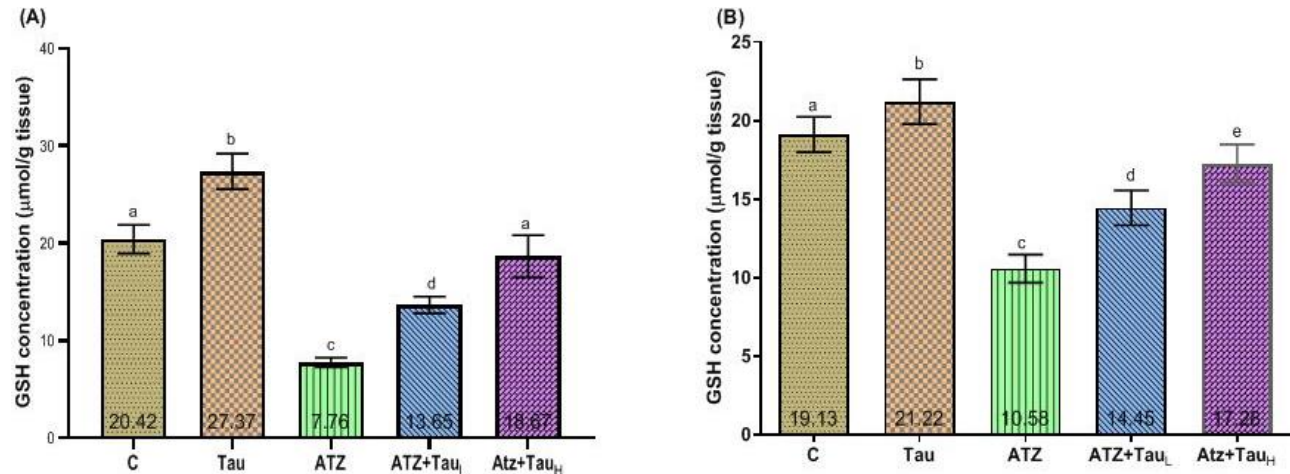

Fig. 3: Effects of ATZ Exposure and Taurine Treatment on Reduced Glutathione (GSH) Concentration in the Liver (A) and Kidney (B) of Rats. Data are Presented as the Mean \pm SD $(\mathrm{N}=7)$. Data with Different Superscripts are Significantly Different $(\mathrm{P}<0.05)$.

\subsection{Hepatic and renal total antioxidant capacity (TAC)}

The total antioxidant capacity in the animals, measured as $\mathrm{Fe}^{2+}$ equivalent was markedly depleted on exposure to ATZ (Figure 4). TAC was reduced by $56 \%$ and $32 \%$ in the hepatic and renal compartments by the pesticide, respectively. Treatment with taurine alone boosted TAC in normal rats by $25 \%$ in the liver while the kidney displayed a value comparable to the control. Taurine co-treatment in ATZ exposed rats, however, restored the antioxidant capacity to values comparable to the control, especially with the high dose.


Fig. 4: Effects of ATZ Exposure and Taurine Treatment on Total Antioxidant Capacity (TAC) in the Liver (A) and Kidney (B) of Rats. Data are Presented as the Mean $\pm \mathrm{SD}(\mathrm{N}=7)$. Data with Different Superscripts are Significantly Different $(\mathrm{P}<0.05)$.

\subsection{Activities of hepatic and renal antioxidant enzymes}

The effects of ATZ on the antioxidant enzymes, SOD and CAT are shown in Figure 5. The activities of the enzymes were significantly decreased in ATZ-exposed animals when compared with control ( $\mathrm{p}<0.05)$. In the liver, SOD and CAT activities were reduced by $49 \%$ and $46 \%$ respectively, compared to the control. On the other hand, renal activities of these enzymes were reduced by $66 \%$ and $54 \%$ respectively. Co-treatment with taurine at high dose caused a full restoration of SOD activity in both liver and kidney, with the same dose also restoring CAT activity in the liver to normal.
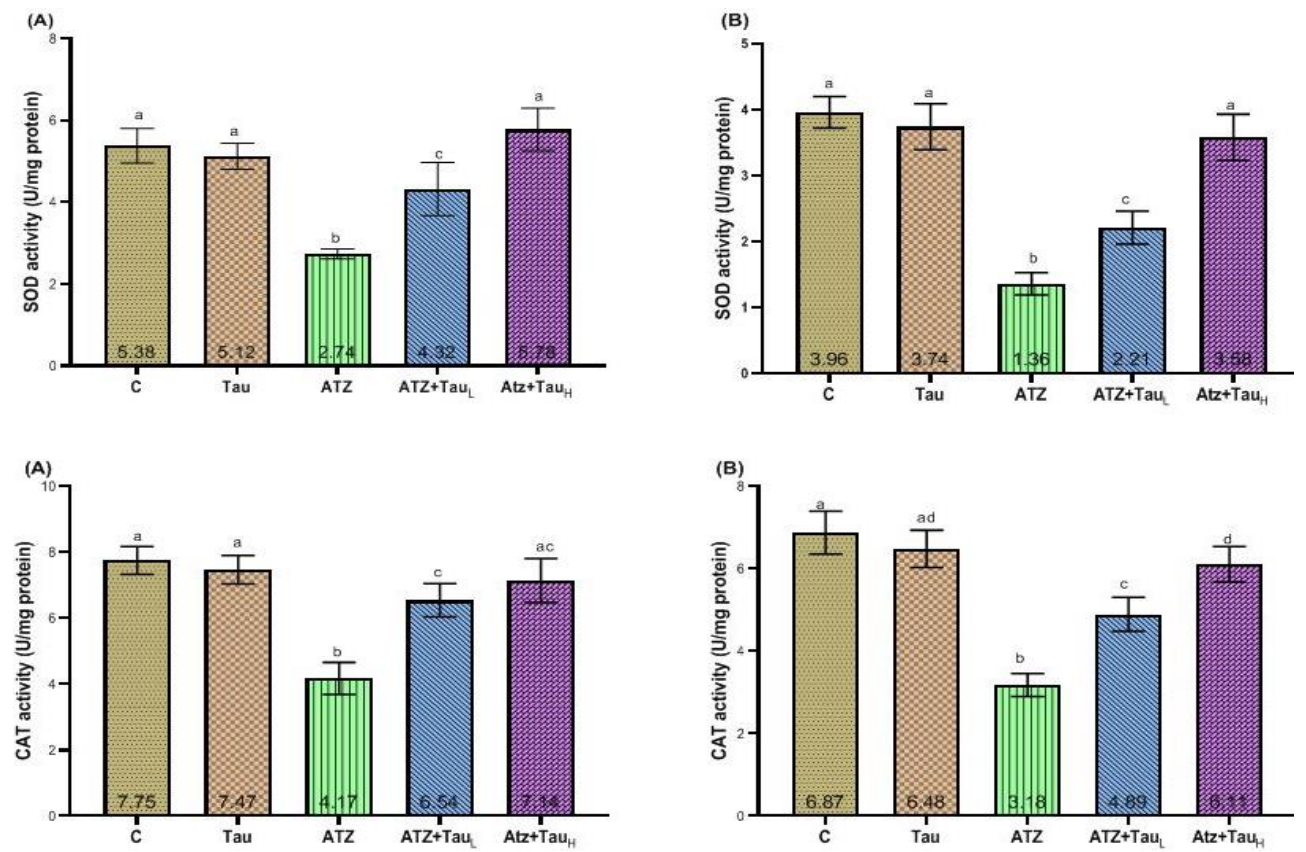

Fig. 5: Effects of ATZ Exposure and Taurine Treatment on Superoxide Dismutase (SOD) and Catalase (CAT) Activities in the Liver (A) and Kidney (B) of Rats. Data are Presented as the Mean $\pm \mathrm{SD}(\mathrm{N}=7)$. Data with Different Superscripts are Significantly Different $(\mathrm{P}<0.05)$. 


\section{Discussion}

The primary cause of subcellular effects of pesticide toxicity may be attributed to oxidative damage. Various studies of exposure to ATZ have suggested a putative role for the generation of free radicals and induction of inflammation during the process. This study therefore, evaluated ATZ-induced oxidative stress in tissues of rats, and its possible attenuation by taurine. To this end, the activities of CAT and SOD along with the concentrations of GSH, TAC, MDA, and AOPP as indices of oxidative stress were determined in the liver and kidney of rats. The animals were orally exposed to a sub-lethal dose of ATZ for 30 days. To further elucidate the role of oxidative stress in the observed hepato-renal injury, taurine, a natural $\beta$ amino acid, with established antioxidant properties was used to modulate the potentials of ATZ in inducing oxidative stress in the liver and kidney.

Oxidative damage is considered a major cause of tissue injuries through the generation of reactive oxygen species (ROS) with the subsequent destruction of proteins, lipids and DNA. Studies have demonstrated that ATZ causes oxidative damage through the generation of free radicals (Jestadi et al. 2014, El-Shenawy et al. 2011). These radicals attack cell membranes, causing their destabilization and disintegration. The increased oxidation reflected as high MDA and AOPP contents on exposure to sub-lethal dose of ATZ in our investigation aligned with these other studies. MDA content is an important indicator of lipid peroxidation, being a major oxidation product of peroxidized polyunsaturated fatty acids. Our study demonstrated that levels of MDA were significantly increased in the ATZ-treated group compared to control. The increase in the hepatic and renal contents of MDA is indicative of excessive lipid peroxidation caused by sublethal exposure to ATZ in the rats. The increased peroxidation and subsequent depletion of cellular antioxidants could therefore, explain the elevated hepatic and renal AOPP levels in the ATZ-treated rats. AOPPs are early markers of oxidative injury resulting from the actions of free radicals on proteins (Cvetkovic et al. 2015). Increase in AOPP level has been reported in mice exposed to ATZ (Gao et al. 2016). Taurine has been shown to act as a scavenger of superoxide, hydroxyl radicals, and singlet molecular oxygen (Zhang et al. 2014). Consistent with these reports is the co-treatment of ATZ with taurine in our study, which significantly decreased lipid peroxidation and protein oxidation in comparison to the group exposed to ATZ alone, leading to the restoration of the organs MDA and AOPP contents to normal levels. Taurine probably prevented the oxidative damage by reducing the formation of cellular oxidants (De Luca et al. 2015). Studies have suggested that taurine conjugates increases the expression of cellular detoxification-related proteins and the promotion of a large variety of antioxidant genes (Kang \& Kim, 2013, Sugiura et al. 2013).

GSH is a major component of the cellular antioxidant defense system. Damage to antioxidant capacity can result from increased oxidation of GSH, as well as, an overall reduction in intracellular concentrations of total glutathione (Izawa et al. 2014). It has been demonstrated that xenobiotics can cause the depletion of intracellular sulfhydryl groups, a process that is a prerequisite for the generation of ROS (Harris \& Hansen 2012). Glutathione and other endogenous antioxidants thus, play a crucial role in cellular defense against xenobiotics induced toxicity. GSH acts by directly scavenging free radicals or by acting as a substrate to GPx and GST during the detoxification of $\mathrm{H}_{2} \mathrm{O}_{2}$, lipid peroxides and electrophiles. In addition, it also prevents the oxidation of SH groups of proteins (Masella et al. 2005). In our study, ATZ exposure caused the depletion of GSH and other endogenous antioxidants, measured as TAC. The reduction in GSH may arise due to increased production of glutathione conjugates or metabolites formed in the tissues. This is important since pesticides are detoxified mainly through GST catalyzed reaction, utilizing GSH, and an increase in GST activity, a protective mechanism against ROS generation, may lead to the exhaustion of GSH content, especially if the radical attack persists. Other workers have reported increased GST activity following exposure to pesticides (El-Demerdash 2011, Singh et al. 2006). Singh et al. reported similar result of GSH depletion following ATZ exposure in erythrocytes (Singh et al. 2010). In addition to the depleted GSH contents and a decrease in total antioxidant capacity in the tissues, lipid peroxidation levels were elevated in the tissues. The deficit in GSH concentrations and TAC probably thus, stemmed from increased ROS levels. The depletion would in turn, could have resulted in a further increase in ROS levels and attendant toxicity, as the effective elimination of the ROS from the cell is impeded, leading to the escalation of oxidative stress (Pramanik et al. 2011). The decrease in GSH contents and reduction of TAC in ATZ-treated group could lead to increased susceptibility of the liver and kidney to free radical damage. However, administration of taurine during ATZ exposure reversed this trend, with the $\beta$-amino acid at the high dose restoring the hepatic GSH concentration and the antioxidant power level back to normal level. Taurine has been reported to reduce consumption of GSH by inhibiting peroxidation reactions (Çetiner et al. 2005). In addition, sharing the same precursor, taurine could increase GSH levels by directing more cysteine into GSH biosynthesis (Thirupathi et al. 2018).

Exposure to ATZ drastically decreased both hepatic and renal activities of the enzymes, SOD and CAT in the animals. The inhibition was however, accompanied by an increase in the activity of GST. Previous studies have shown the inhibitory action of ATZ exposure on SOD and CAT (Jestadi et al. 2014; Santos \& Martinez 2012). However, other studies at lower ATZ doses and shorter durations have reported stimulation of these enzymes (Singh et al. 2010). SOD plays a prominent role in cellular antioxidant defense system by catalyzing the dismutation of superoxide radicals into molecular oxygen and hydrogen peroxide $\left(\mathrm{H}_{2} \mathrm{O}_{2}\right)$. The combined actions of SOD and glutathione peroxidase neutralize the formed $\mathrm{H}_{2} \mathrm{O}_{2}$ in all vertebrates (Mates 2000). The activities of SOD and CAT are in tandem, with CAT protecting SOD against inactivation by $\mathrm{H}_{2} \mathrm{O}_{2}$ while SOD reciprocally protects CAT against inhibition by superoxide anions (Ighodaro \& Akinloye 2018). Changes in levels of these cellular enzymes may alter this delicate equilibrium and tilt the balance towards oxidative stress. The decrease in hepatic and renal SOD activity in ATZ exposed rats in this study is suggestive of an increased generation of superoxide radical and other ROS, the consequent of which is oxidative damage to these tissues. The increased presence of superoxide radicals may thus, be responsible for the inhibition of CAT in these tissues. When xenobiotics such as ATZ cause lipid peroxidation/oxidative stress, as a form of defense mechanism antioxidant enzyme activities undergo some modulation to accommodate the perturbation, reflected mainly in the stimulation of these enzymes. But as the enzymes are increasingly utilized for the detoxification of these free radicals, their activity eventually reduce as seen in our study (Gao et al. 2016). Co-administration with taurine however, caused a restoration of the enzymes' activities probably through its ability to scavenge free radicals and thus, boosted and sustained the activity of these enzymes. Cellular generation of ROS can damage antioxidant enzymes that are ordinarily capable of preventing oxidative stress, as observed in our study. The sensitivity of these enzymes to oxidative damage and the ability of taurine to limit oxidative stress may explain the restoration of their activities by the amino acid.

\section{Conclusion}

The results of this study demonstrated that atrazine exposure induced oxidative stress in rat liver and kidney, further providing evidence of atrazine induced oxidative stress. Co-treatment with taurine attenuated and generally normalized the toxic effects of ATZ. Part of the beneficial effect of taurine in our study, may be ascribed to its suppression of oxidative burden in tissues of ATZ-exposed rats. Thus, 
taurine appeared to be a promising agent for protection against ATZ-induced oxidative damage. Dietary supplementation with taurine could be an easy and useful method in protecting occupationally exposed workers and limiting toxicity associated with atrazine exposure.

\section{References}

[1] Abarikwu SO, Duru QC, Njoku RC, Amadi BA, Tamunoibuomie A \& Keboh E (2017) Effects of co-exposure to atrazine and ethanol on the oxidative damage of kidney and liver in Wistar rats. Renal Failure 39, 588-596. https://doi.org/10.1080/0886022X.2017.1351373.

[2] Aebi H (1974) Catalase. Methods of enzymatic analysis. Elsevier, 673-684. https://doi.org/10.1016/B978-0-12-091302-2.50032-3.

[3] Alam SS, Hafiz NA \& El-Rahim AHA (2011) Protective role of taurine against genotoxic damage in mice treated with methotrexate and tamoxfine. Environmental Toxicology and Pharmacology 31, 143-152. https://doi.org/10.1016/j.etap.2010.10.001.

[4] Balkan J, Parldar FH, Dogru-Abbasoglu S, Aykaç-Toker G \& Uysal M (2005) The effect of taurine or betaine pretreatment on hepatotoxicity and prooxidant status induced by lipopolysaccharide treatment in the liver of rats. European Journal of Gastroenterology \& Hepatology $17,917-921$. https://doi.org/10.1097/00042737-200509000-00006.

[5] Benzie IF \& Strain JJ (1996) The ferric reducing ability of plasma (FRAP) as a measure of "antioxidant power": the FRAP assay. Analytical Biochemistry 239, 70-76. https://doi.org/10.1006/abio.1996.0292.

[6] Bonvallot N, Canlet C, Blas-Y-Estrada F, Gautier R, Tremblay-Franco M, Chevolleau S, Cordier S \& Cravedi JP (2018) Metabolome disruption of pregnant rats and their offspring resulting from repeated exposure to a pesticide mixture representative of environmental contamination in Brittany. PloS one 13, e0198448. https://doi.org/10.1371/journal.pone.0198448.

[7] Buege JA \& Aust SD (1978) Microsomal lipid peroxidation. Methods in Enzymology. Elsevier, 302-310. https://doi.org/10.1016/S00766879(78)52032-6.

[8] Çetiner M, Şener G, Şehirli AÖ, Ekşioğlu-Demiralp E, Ercan F, Sirvanci S, Gedik N, Akpulat S, Tecimer T \& Yeğen BC (2005) Taurine protects against methotrexate-induced toxicity and inhibits leukocyte death. https://doi.org/10.1016/j.taap.2005.03.009.

[9] Toxicology and Applied Pharmacology 209, 39-50.

[10] Chen C, Xia S, He J, Lu G, Xie Z \& Han H (2019) Roles of taurine in cognitive function of physiology, pathologies and toxication. Life Sciences 231, 116584. https://doi.org/10.1016/j.lfs.2019.116584.

[11] Cvetkovic T, Stankovic J, Najman S, Pavlovic D, Stokanovic D, Vlajkovic S, Dakovic-Bjelakovic M, Cukuranovic J, Zivkpvic V \& Stefanovic V (2015) Oxidant and antioxidant status in experimental rat testis after testicular torsion/detorsion. International Journal of Fertility \& Sterility 9 , 121.

[12] Dawson Jr R, Biasetti M, Messina S \& Dominy J (2002) The cytoprotective role of taurine in exercise-induced muscle injury. Amino Acids 22, 309-324. https://doi.org/10.1007/s007260200017.

[13] De Luca A, Pierno S \& Camerino DC (2015) Taurine: the appeal of a safe amino acid for skeletal muscle disorders. Journal of Translational Medicine 13, 243. https://doi.org/10.1186/s12967-015-0610-1.

[14] El-Demerdash FM (2011) Oxidative stress and hepatotoxicity induced by synthetic pyrethroids-organophosphate insecticides mixture in rat. Journal of Environmental Science and Health, Part C 29, 145-158. https://doi.org/10.1080/10590501.2011.577679.

[15] El-Shenawy N, El-Ahmary B \& Al-Eisa R (2011) Mitigating effect of ginger against oxidative stress induced by atrazine herbicides in mice liver and kidney. Journal of Biofertilizers \& Biopesticides 2, 107. https://doi.org/10.4172/2155-6202.1000107.

[16] Feng J, Liu A \& Zhu W (2017) Toxic Effects of Atrazine on Reproductive and Immune Systems in Animal Models. Reprod System \& Sex Disorders 6: 2. https://doi.org/10.4172/2161-038X.1000208

[17] Gao S, Wang Z, Zhang C, Jia L \& Zhang Y (2016) Oral exposure to atrazine induces oxidative stress and calcium homeostasis disruption in spleen of mice. Oxidative Medicine and Cellular Longevity 2016. https://doi.org/10.1155/2016/7978219.

[18] Harris C \& Hansen JM (2012) Oxidative stress, thiols, and redox profiles. Developmental Toxicology. Springer, 325-346. https://doi.org/10.1007/978-1-61779-867-2_21.

[19] Heidari R, Babaei H \& Eghbal MA (2013) Cytoprotective effects of taurine against toxicity induced by isoniazid and hydrazine in isolated rat hepatocytes. Archives of Industrial Hygiene and Toxicology 64, 201-210. https://doi.org/10.2478/10004-1254-64-2013-2297.

[20] Ighodaro O \& Akinloye O (2018) First line defence antioxidants-superoxide dismutase (SOD), catalase (CAT) and glutathione peroxidase (GPX): Their fundamental role in the entire antioxidant defence grid. Alexandria Journal of Medicine 54, 287-293. https://doi.org/10.1016/j.ajme.2017.09.001.

[21] Izawa K, Okada M, Sumitomo K, Nakagawa N, Aizawa Y, Kawabe J, Kikuchi K \& Hasebe N (2014) Impaired glutathione redox system paradoxically suppresses angiotensin II-induced vascular remodeling. PloS one 9, e108115. https://doi.org/10.1371/journal.pone.0108115.

[22] Jestadi DB, Phaniendra A, Babji U, Srinu T, Shanmuganathan B \& Periyasamy L (2014) Effects of short term exposure of atrazine on the liver and kidney of normal and diabetic rats. Journal of Toxicology 2014, 536759. https://doi.org/10.1155/2014/536759.

[23] Jong CJ, Azuma J \& Schaffer S (2012) Mechanism underlying the antioxidant activity of taurine: prevention of mitochondrial oxidant production Amino Acids 42, 2223-2232. https://doi.org/10.1007/s00726-011-0962-7.

[24] Kang IS \& Kim C (2013) Taurine chloramine administered in vivo increases NRF2-regulated antioxidant enzyme expression in murine peritoneal macrophages. Advanced Experimental and Medical Biology 775, 259-267. https://doi.org/10.1007/978-1-4614-6130-2 22.

[25] Klaassen CD \& Amdur MO (2013) Casarett and Doull's Toxicology: The Basic Science of Poisons. McGraw-Hill New York.

[26] Lowry OH, Rosebrough NJ, Farr AL, Randall RJ (1951) Protein measurement with the Folin phenol reagent. Journal of Biological Chemistry 193, 265-275.

[27] Lushchak VI, Matviishyn TM, Husak VV, Storey JM \& Storey KB (2018) Pesticide toxicity: a mechanistic approach. Excli JournaL 17, 11011136.

[28] Masella R, Di Benedetto R, Varì R, Filesi C \& Giovannini (2005) Novel mechanisms of natural antioxidant compounds in biological systems: involvement of glutathione and glutathione-related enzymes. The Journal of Nutritional Biochemistry 16, 577-586. https://doi.org/10.1016/j.jnutbio.2005.05.013.

[29] Mates J (2000) Effects of antioxidant enzymes in the molecular control of reactive oxygen species toxicology. Toxicology 153, 83-104. https://doi.org/10.1016/S0300-483X(00)00306-1.

[30] Misra HP \& Fridovich I (1972) The role of superoxide anion in the autoxidation of epinephrine and a simple assay for superoxide dismutase. Journal of Biological Chemistry 247, 3170-3175.

[31] Moron MS, Depierre JW \& Mannervik B (1979) Levels of glutathione, glutathione reductase and glutathione S-transferase activities in rat lung and liver. Biochimica et Biophysica Acta (BBA)-General Subjects 582, 67-78. https://doi.org/10.1016/0304-4165(79)90289-7.

[32] Ozden S, Catalgol B, Gezginci-Oktayoglu S, Karatug A, Bolkent S \& Alpertunga B (2013) Acute effects of methiocarb on oxidative damage and the protective effects of vitamin $\mathrm{E}$ and taurine in the liver and kidney of Wistar rats. Toxicology and industrial health 29 , 60-71. https://doi.org/10.1177/0748233712446719.

[33] Pramanik KC, Boreddy SR \& Srivastava SK (2011) Role of mitochondrial electron transport chain complexes in capsaicin mediated oxidative stress leading to apoptosis in pancreatic cancer cells. PloS one 6, e20151. https://doi.org/10.1371/journal.pone.0020151.

[34] Ross MK, Jones TL \& Filipov NM (2009) Disposition of the herbicide 2-chloro-4-(ethylamino)-6-(isopropylamino)-s-triazine (Atrazine) and its major metabolites in mice: a liquid chromatography/mass spectrometry analysis of urine, plasma, and tissue levels. Drug Metabolism and Disposition 37, 776-786. https://doi.org/10.1124/dmd.108.024927.

[35] Roy A \& Sil PC (2012) Tertiary butyl hydroperoxide induced oxidative damage in mice erythrocytes: Protection by taurine. Pathophysiology 19, 137-148. https://doi.org/10.1016/j.pathophys.2012.05.001. 
[36] Santos TG \& Martinez CB (2012) Atrazine promotes biochemical changes and DNA damage in a Neotropical fish species. Chemosphere 89, 11181125. https://doi.org/10.1016/j.chemosphere.2012.05.096.

[37] Schaffer S \& Kim HW (2018) Effects and mechanisms of taurine as a therapeutic agent. Biomolecules \& Therapeutics 26, $225-241$. https://doi.org/10.4062/biomolther.2017.251.

[38] Schaffer SW, Jong CJ, Ramila K \& Azuma J (2010) Physiological roles of taurine in heart and muscle. Journal of Biomedical Science 17, S2. https://doi.org/10.1186/1423-0127-17-S1-S2.

[39] Singh M, Sandhir R \& Kiran R (2006) Erythrocyte antioxidant enzymes in toxicological evaluation of commonly used organophosphate pesticides. Indian Journal of Expermental Biology 44, 580-583.

[40] Singh M, Sandhir R \& Kiran R (2010) Oxidative stress induced by atrazine in rat erythrocytes: mitigating effect of vitamin E. Toxicology Mechanisms and Methods 20, 119-126. https://doi.org/10.3109/15376511003606253.

[41] Sugiura H, Okita S, Kato T, Naka T, Kawanishi S, Ohnishi S, Oshida Y \& Ma N (2013) Protection by taurine against INOS-dependent DNA damage in heavily exercised skeletal muscle by inhibition of the NF- $\mathrm{B}$ signaling pathway. Advanced Expermental and Medicinal Biology 775 , 237-246. https://doi.org/10.1007/978-1-4614-6130-2_20.

[42] Thirupathi A, Freitas S, Sorato HR, Pedroso GS, Effting PS, Damiani AP, Andrade VM, Nesi RT, Gupta RC, Muller AP \& Pinho RA (2018) Modulatory effects of taurine on metabolic and oxidative stress parameters in a mice model of muscle overuse. Nutrition 54, $158-164$. https://doi.org/10.1016/j.nut.2018.03.058.

[43] Witko-Sarsat V, Friedlander M, Capeillère-Blandin C, Nguyen-Khoa T, Zingraff J, Jungers P \& Deschamps-Latscha B (1996) Advanced oxidation protein products as a novel marker of oxidative stress in uremia. Kidney International 49, 1304-1313. https://doi.org/10.1038/ki.1996.186.

[44] Yildirim Z \& Kilic N (2011) Effects of taurine and age on cerebellum antioxidant status and oxidative stress. International Journal of Gerontology 5, 166-170. https://doi.org/10.1016/j.ijge.2011.09.019.

[45] Zhang Z, Liu D, Yi B, Liao Z, Tang L, Yin D \& He M (2014) Taurine supplementation reduces oxidative stress and protects the liver in an ironoverload murine model. Molecular Medicine Reports 10, 2255-2262. https://doi.org/10.3892/mmr.2014.2544. 